\title{
Preoperative prediction of surgical outcome in advanced ovarian cancer by computed tomographic scan and Eastern Cooperative Oncology Group-performance status
}

\author{
Nithya S. ${ }^{1}$, Jayalakshmi D. ${ }^{1 *}$, Deepak Barathi ${ }^{2}$, Biswajit Dubashi ${ }^{3}$
}

\begin{abstract}
${ }^{1}$ Department of Obstetrics and Gynecology, ${ }^{2}$ Department of Radio Diagnosis, ${ }^{3}$ Department of Medical Oncology, JIPMER, Puducherry, India
\end{abstract}

Received: 25 June 2018

Accepted: 26 July 2018

\author{
*Correspondence: \\ Dr. Jayalakshmi D., \\ E-mail: dr_jaylakshmi@yahoo.com
}

Copyright: ( $\odot$ the author(s), publisher and licensee Medip Academy. This is an open-access article distributed under the terms of the Creative Commons Attribution Non-Commercial License, which permits unrestricted non-commercial use, distribution, and reproduction in any medium, provided the original work is properly cited.

\begin{abstract}
Background: Ovarian cancer represents the sixth most common cancer in women with almost 2 lakh new cases diagnosed every year. Present study was done to investigate the role of preoperative Computed Tomographic scan (CT) and Eastern Cooperative Group Performance Status (ECOG-PS) in the prediction of surgical outcome in advanced ovarian cancer.

Methods: It is a Prospective cohort study of 41 cases of advanced ovarian cancer. Patients fulfilling the inclusion criteria were included after obtaining informed consent. A detailed history with general examination of the patient and relevant preoperative investigations were carried out. A preoperative Contrast Enhanced Computerised Tomography scan (CECT) was obtained and relevant CT parameters were analysed by a senior radiologist. Surgical outcome and its correlation with the CT scan findings and ECOG-PS were calculated by statistical analysis.

Results: Among the 41 patients 23(56\%) had optimal cytoreduction. Among the CT parameters, omental extension to spleen, stomach, lesser sac (specificity-100\%, PPV-100\%, NPV-60.5\%), suprarenal lymph nodes $>1 \mathrm{~cm}$ (specificity$100 \%$, PPV-100\%, NPV-59\%), infrarenal lymph nodes >2 cm (specificity-95.7\%\%, PPV-66.7\%, NPV-59.7\%) were found as better predictors for suboptimal cytoreduction. ECOG-PS didn't have a statistically significant association with surgical outcome.

Conclusions: Presence of omental extension to adjacent structures and suprarenal lymphnodes on CT scan predicted suboptimal cytoreduction with $100 \%$ specificity. Though CT served as a valid tool in the preoperative prediction of surgical outcome in advanced ovarian malignancy, these results cannot be extrapolated to the general population nor can this be universally applied in determining the mode of treatment. Future studies are required to validate the findings of the present study on a larger scale.
\end{abstract}

Keywords: Cytoreduction, CT scan, ECOG-PS, Ovarian cancer, Predictive models

\section{INTRODUCTION}

Ovarian cancer represents the sixth most common cancer in women with almost 2 lakh new cases diagnosed every year. ${ }^{1,2}$ It is one of the most aggressive genital malignancy occurring mostly in the $6^{\text {th }}$ and $7^{\text {th }}$ decades. The poor outcome of the disease is attributed to the fact that almost two third of the cases present in advanced stage with 5-year survival rate of $25-50 \%{ }^{2}$

The management of advanced ovarian cancer requires multimodality therapy to achieve the most successful outcome, which is ideally by primary optimal cytoreductive surgery followed by chemotherapy. 
However, some women may not be appropriate candidates for primary surgery because of associated medical conditions or unresectable disease for whom, neoadjuvant chemotherapy (NACT) with interval debulking could serve as a better option than primary debulking surgery. ${ }^{3}$

The theoretical benefits of primary cytoreductive surgery in ovarian cancer are that, it can reduce the adverse metabolic effects of a large tumor burden and removes dormant or chemotherapy resistant clones of cells, thereby improving the chances of its response to adjuvant treatment. However, the most important benefit of primary cytoreduction is its robust and consistent inverse relationship with the amount of residual disease and subsequent survival outcome. ${ }^{2}$ The surgical outcome may be optimal or suboptimal. Currently the definition of optimal cytoreduction by Gynaecologic Oncology Group (GOG) is maximal diameter of the residual tumor being $\leq 1 \mathrm{~cm} \cdot{ }^{1,4-6}$ Henceforth, the most important factor determining the prognosis of the disease is maximal diameter of residual tumor persistent after surgery. ${ }^{4}$

The 5 year survival rate for the patients with optimal cytoreduction and no visible disease is $60 \%$, whereas for optimal cytoreduction with visible residual disease, it is $35 \%$. But the 5 year survival rate is only $20 \%$ for the patients who had undergone suboptimal cytoreduction. ${ }^{2}$ Though the survival benefit of optimal primary cytoreductive surgery has been well established in advanced ovarian cancer, many of these patients undergo radical procedures to achieve the optimal cytoreduction and hence exposed to significant surgical morbidity, which affects the quality of life. Almost 25-30\% of the radical procedures are associated with increased blood loss, operative time, hospital stay and other comorbidities. $^{2}$ The 30-day mortality rate for women undergoing primary cytoreduction for ovarian cancer range between $1-3 \% .{ }^{4}$ Considering the fact that the patients undergoing suboptimal cytoreduction are experiencing this significant surgical morbidity, but with minimal survival benefits, it becomes essential to identify this subset of patients preoperatively to offer them an alternate treatment modality with neoadjuvant chemotherapy followed by interval debulking in order to improve the quality of life thereby, improvising the standard of care. ${ }^{5}$ The critical question that arises in this regard is about the prediction of feasibility of optimal cytoreduction to optimise the treatment modality.

The aim of the current study is to assess the role of Computed Tomographic (CT) scan and ECOG-PS in preoperative prediction of optimal cytoreduction in advanced ovarian cancer in our set up.

\section{METHODS}

Between October 2013 to July 2015, all patients with clinical and radiographic suspicion of advanced (stage III-IV) ovarian cancer planned for cytoreductive surgery, irrespective of prior treatment were enrolled in the study at Obstetrics and Gynaecology department, Jawaharlal Institute of Postgraduate Medical Education and Research (JIPMER), Puducherry, India.

Routine staging work up including complete physical and gynaecological examination, Ca125 serum level assessment, chest X-rays, and abdomino-pelvic CECT scan were performed. ECOG performance status (ECOGPS) was also noted. Patients were included in the study based on the clinical or radiographic suspicion of advanced stage ovarian tumor by the presence of at least any two of the following - Presence of gross ascites, pouch of douglas nodule, Hard fixed irregular mass on clinical examination, radiographic evidence of metastatic disease, and elevated Ca125 levels (>200 IU/ml). Patients with ECOG-PS $>2$, medically unfit patients for surgery and presence of contraindications for CECT were excluded from the study. Approval was obtained from Institute Ethical Committee.

A preoperative CECT was obtained using the IV contrast iapomidal after an informed consent. Images were taken in craniocaudal direction with $2 \mathrm{~mm}$ thickness for assessing the extent of the disease. The relevant CECT parameters such as Peritoneal thickening, peritoneal implants $>2 \mathrm{~cm}$, Bowel mesentery involvement, Omental extension to spleen, stomach, lesser sac, Pelvic sidewall involvement and/or hydroureter, Suprarenal aortic lymph nodes $>1 \mathrm{~cm}$, Infrarenal aortic lymph nodes $>2 \mathrm{~cm}$, Liver metastases, Large volume ascites $(>500 \quad \mathrm{ml})$, Diaphragmatic disease were analysed by a senior radiologist. For the subgroup of patients with advanced ovarian malignancy having received NACT, the clinical characteristics of the ovarian tumor and CT scan just prior to interval debulking were considered.

Staging laparotomy and cytoreduction were performed by gynaecologists. Surgical removal of tumour masses, along with total abdominal hysterectomy, bilateral salpingo-oophorectomy and omentectomy were performed. Patients were staged according to FIGO staging system (1988). Maximal surgical effort to achieve residual disease $<1 \mathrm{~cm}$ has been attempted in all patients. Surgical outcome (optimal / suboptimal cytoreduction) and its correlation with the ECOG-PS and CT scan findings were calculated by statistical analysis.

The distribution of data for CT parameters, ECOG- PS were expressed as frequencies and percentages. The comparisons of these categorical and ordinal data between the subgroups were carried out by using Chisquare test. Sensitivity, specificity along with positive and negative predictive values (PPVand NPV) were used to assess the predictive power of $\mathrm{CT}$ parameters. Statistical analysis was carried out at 5\% level of significance and $\mathrm{p}$ value $<0.05$ was considered as significant. Statistical analysis was performed using SPSS -20 software. 


\section{RESULTS}

At the end of enrolment, the final study included 41 patients. Characteristics of the patients, final FIGO staging and surgical outcome are summarised in Table 1. Among the 41 patients $37(90.2 \%)$ were having ECOGPS of 0/1, only 4 patients had ECOG-PS 2.

Table 1: Characteristics of the patients enrolled.

\begin{tabular}{|ll|}
\hline Characteristics & No. of patients (\%) \\
\hline All cases & 41 \\
\hline Age(years) & \\
\hline$<60$ & $31(75.6)$ \\
\hline$\geq 60$ & $10(24.4)$ \\
\hline ECOG-PS & $37(90.2)$ \\
\hline $0-1$ & $4(9.8)$ \\
\hline 2 & \\
\hline Debulking surgery & $16(39)$ \\
\hline Primary & $25(61)$ \\
\hline Interval (Post NACT) & \\
\hline FIGO Stage & $5(12.2)$ \\
\hline Stage II & $30(73.2)$ \\
\hline Stage III & $6(14.6)$ \\
\hline Stage IV & \\
\hline CA 125(IU/ml) & $22(53.7)$ \\
\hline$<600$ & $19(46.3)$ \\
\hline$>600$ & \\
\hline Surgical outcome & $23(56.1)$ \\
\hline Optimal cytoreduction & $18(43.9)$ \\
\hline Suboptimal cytoreduction & \\
\hline Perioperative complications & $17(41.5)$ \\
\hline Haemorrhage & $2(4.9)$ \\
\hline Bowel /bladder injury & $2(4.9)$ \\
\hline Paralytic ileus & $2(4.9)$ \\
\hline Relaparotomy & \\
\hline Wound infection & \\
\hline
\end{tabular}

The study population was selected only based on clinical or radiographic suspicion of advanced stage disease but at staging laparotomy only 36 patients had advanced stage disease. Almost 46\% patients had $\mathrm{Ca} 125$ levels >600 $\mathrm{mIU} / \mathrm{ml}$. Among the study subjects $25(61 \%)$ underwent interval debulking and $16(39 \%)$ of them underwent primary debulking. Overall optimal cytoreduction rate was $56 \%$.

Analysis of association between clinical characteristics like age, menopausal status, ECOG-PS and the type of debulking with surgical outcome are depicted in Table 2.

Age, Menopausal status and ECOG-PS didn't have a significant association with surgical outcome. Though type of surgery and surgical outcome didn't show statistically significant association, the optimal cytoreduction rate was higher $(68 \%)$ in the interval debulking group than primary debulking $(37.5 \%)$ which is the effect of neoadjuvant chemotherapy.

Table 2: Association between clinical characteristics and surgical outcome.

\begin{tabular}{|c|c|c|c|}
\hline $\begin{array}{l}\text { Clinical } \\
\text { character }\end{array}$ & $\begin{array}{l}\text { Optimal } \\
\text { cyto- } \\
\text { reduction } \\
\mathrm{n}=\mathbf{2 3}\end{array}$ & $\begin{array}{l}\text { Suboptimal } \\
\text { cyto- } \\
\text { reduction } \\
n=18\end{array}$ & $\begin{array}{l}\text { Statistical } \\
\text { Significance } \\
\text { p value* }\end{array}$ \\
\hline \multicolumn{4}{|l|}{ Age } \\
\hline$<60 y r s$ & $17(55 \%)$ & $14(45 \%)$ & \multirow{2}{*}{0.77} \\
\hline$>60 \mathrm{yrs}$ & $6(60 \%)$ & $4(40 \%)$ & \\
\hline \multicolumn{4}{|c|}{ Menopaual status } \\
\hline Premenopause & $15(68.2 \%)$ & $7(31.8 \%)$ & \multirow{2}{*}{0.12} \\
\hline Postmenopausal & $8(42 \%)$ & $11(58 \%)$ & \\
\hline \multicolumn{4}{|l|}{ ECOG-PS } \\
\hline 0 and 1 & $22(60 \%)$ & $15(40 \%)$ & \multirow[b]{2}{*}{0.24} \\
\hline 2 & $1(25 \%)$ & $3(75 \%)$ & \\
\hline \multicolumn{4}{|l|}{ Type of surgery } \\
\hline $\begin{array}{l}\text { Primary } \\
\text { debulking }\end{array}$ & $17(68 \%)$ & $8(32 \%)$ & \multirow{2}{*}{0.11} \\
\hline $\begin{array}{l}\text { Interval } \\
\text { debulking }\end{array}$ & $6(37.5 \%)$ & $10(62.5 \%)$ & \\
\hline
\end{tabular}

Table 3: Univariate analysis of predictors of surgical outcome on CT.

\begin{tabular}{|c|c|c|c|}
\hline CT Parameter & $\begin{array}{l}\text { Optimal } \\
\text { cytoreduction } \\
\mathbf{n = 2 3}\end{array}$ & $\begin{array}{l}\text { Suboptimal } \\
\text { cytoreduction } \\
\mathrm{n}=18\end{array}$ & $\begin{array}{l}\text { Statistical } \\
\text { Significance } \\
\text { p value }\end{array}$ \\
\hline Peritoneal thickening, peritoneal implants $>2 \mathrm{~cm}$ & $10(45.5 \%)$ & $12(54.5 \%)$ & 0.209 \\
\hline Bowel mesentery involvement & $4(44.4 \%)$ & $5(55.6 \%)$ & 0.471 \\
\hline Omental extension (spleen, stomach, lesser sac) & $0(0 \%)$ & $3(100 \%)$ & 0.07 \\
\hline Pelvic sidewall involvement and/or hydroureter & $4(57.1 \%)$ & $3(42.9 \%)$ & 1.000 \\
\hline Suprarenal aortic lymph nodes $>1 \mathrm{~cm}$ & $0(0 \%)$ & $2(100 \%)$ & 0.187 \\
\hline Infrarenal-aortic lymph nodes $>2 \mathrm{~cm}$ & $1(33.3 \%)$ & $2(66.7 \%)$ & 0.573 \\
\hline $\begin{array}{l}\text { Superficial liver metastases }>2 \mathrm{~cm} \text { and/or intra- } \\
\text { parenchymal liver metastases of any size }\end{array}$ & $1(50 \%)$ & $1(50 \%)$ & 1.000 \\
\hline Large volume ascites $(>500 \mathrm{ml})$ & $7(43.8 \%)$ & $9(56.2 \%)$ & 0.334 \\
\hline Diaphragmatic disease & $4(50 \%)$ & $4(50 \%)$ & 0.500 \\
\hline
\end{tabular}


Table 3 represents univariate analysis of CT parameters. Although statistically not significant, all the patients who had omental extension to spleen, stomach, lesser sac (p$0.07)$ and suprarenal aortic lymph node $>1 \mathrm{~cm}(\mathrm{p}-0.187)$ ended up having suboptimal debulking surgery. Subgroup analysis was performed after dividing the patients into primary debulking group and interval debulking group. Even on subgroup analysis none of the CT parameters had statistically significant association with surgical outcome.

Association of intraoperative findings with the surgical outcome were analysed results are depicted in Table 4. Presence of ascites, involvement of bladder, large intestine, liver and peritoneum were significantly ( $p$ $<0.05)$ associated with suboptimal debulking. None of the patient with liver parenchymal involvement had optimal cytoreduction. Agreement analysis was performed between CECT findings and intraoperative findings which revealed only fair agreement.

Table 4: Univariate analysis of intraoperative findings in the prediction of surgical outcome.

\begin{tabular}{|lll|l|}
\hline $\begin{array}{l}\text { Tumor } \\
\text { involvement }\end{array}$ & $\begin{array}{l}\text { Optimal } \\
\text { cyto- } \\
\text { reduction } \\
\mathrm{n=23}\end{array}$ & $\begin{array}{l}\text { Suboptimal } \\
\text { cyto- } \\
\text { reduction } \\
\mathrm{n}=18\end{array}$ & $\begin{array}{l}\text { Statistical } \\
\text { Significance } \\
\text { p value* }\end{array}$ \\
\hline Ascites & $9(39 \%)$ & $14(61 \%)$ & $0.025^{*}$ \\
\hline $\begin{array}{l}\text { UV fold/ } \\
\text { bladder }\end{array}$ & $7(33.3 \%)$ & $14(66.7 \%)$ & $0.004^{*}$ \\
\hline $\begin{array}{l}\text { Large } \\
\text { intestine }\end{array}$ & $4(26.7 \%)$ & $11(73.3 \%)$ & $0.008^{*}$ \\
\hline Liver & $0(0 \%)$ & $5(100 \%)$ & $0.011^{*}$ \\
\hline Peritoneum & $13(43.3 \%)$ & $17(56.7 \%)$ & $0.011^{*}$ \\
\hline
\end{tabular}

Table 5: ECOG-PS and CT parameters in prediction of suboptimal cytoreduction.

\begin{tabular}{|lllll|}
\hline Parameter & Sensitivity & Specificity & PPV & NPV \\
\hline Peritoneal thickening, peritoneal implants $>2 \mathrm{~cm}$ & $66.7 \%$ & $56.5 \%$ & $54.5 \%$ & $68.4 \%$ \\
\hline Bowel mesentery involvement & $38.5 \%$ & $82.6 \%$ & $55.5 \%$ & $59.4 \%$ \\
\hline Omental extension (spleen, stomach, lesser sac) & $16.7 \%$ & $100 \%$ & $100 \%$ & $60.5 \%$ \\
\hline Pelvic sidewall involvement and/or hydroureter & $16.7 \%$ & $82.6 \%$ & $42.9 \%$ & $55.9 \%$ \\
\hline Suprarenal aortic lymph nodes $>1 \mathrm{~cm}$ & $11.1 \%$ & $100 \%$ & $100 \%$ & $59 \%$ \\
\hline Infrarenal-aortic lymph nodes $>2 \mathrm{~cm}$ & $11.1 \%$ & $95.7 \%$ & $66.7 \%$ & $59.7 \%$ \\
\hline Liver metastases & $5.5 \%$ & $95.7 \%$ & $50 \%$ & $56.4 \%$ \\
\hline Large volume ascites $(>500 \mathrm{ml})$ & $50 \%$ & $69.6 \%$ & $56.2 \%$ & $64 \%$ \\
\hline Diaphragmatic disease & $22.2 \%$ & $82.6 \%$ & $50 \%$ & $57.6 \%$ \\
\hline ECOG-PS & $16.7 \%$ & $95.7 \%$ & $60 \%$ & $59.5 \%$ \\
\hline
\end{tabular}

Table 5 illustrates the sensitivity, specificity, PPV and NPV of each parameter in predicting surgical outcome. Among the CT parameters, omental extension to stomach, lesser sac and spleen had specificity of $100 \%$, PPV of $100 \%$ and NPV of $60.5 \%$. Similarly, suprarenal aortic node involvement had specificity, PPV and NPV of $100 \%, 100 \%$, and $59 \%$ respectively. But none of the parameter had good sensitivity in predicting suboptimal cytoreduction. Omental extension to lesser sac, spleen and stomach had accuracy of $63.4 \%$ in the prediction of suboptimal cytoreduction. ECOG-PS has $95.7 \%$ specificity and $61 \%$ accuracy in the prediction of suboptimal cytoreduction.

\section{DISCUSSION}

In present study, omental extension to stomach, spleen, lesser sac, involvement of suprarenal lymph node, infrarenal lymph node, liver metastasis, bowel mesentery involvement and diaphragmatic involvement were found to have higher specificity, PPV and NPV in the prediction of suboptimal cytoreduction indicating that, it was not feasible to achieve an optimal cytoreduction in the presence of these parameters.

This study revealed that clinical characteristics were not much useful in the prediction of surgical outcome, whereas study by Ferrandina et al showed that ECOG-PS was more accurate in predicting the surgical outcome when compared to other clinical variables. ${ }^{7}$ ECOG-PS had specificity of $91.9 \%$, PPV and NPV of $54 \%$ and $85.7 \%$ respectively in the prediction of suboptimal cytoreduction in Ferrandina et al study. ${ }^{7}$

Various studies have been performed to develop a CT based predictive model. ${ }^{4,5,8-11}$ Dowdy et al had evaluated 17 CT parameters in their study to predict the surgical outcome..$^{5}$ Among the 17 parameters, diffuse peritoneal thickening (DPT), diaphragm or lung base involvement, bowel encasement, ascites on two-thirds or more of the CT scans, and omental extension into adjacent structures were statistically significant in the prediction of suboptimal cytoreduction ( $\mathrm{p}<0.05$ ), but on multivariate analysis the only independent predictor for surgical outcome was DPT. ${ }^{5}$ A multi-institutional reciprocal 
validation study by Axtell et al showed that diaphragm disease $>2 \mathrm{~cm}$ and large bowel mesentery involvement were significant predictors for suboptimal cytoreduction. ${ }^{11}$ Mousavi et al studied ASA status, CA 125, CT parameters in the preoperative prediction of suboptimal cytoreduction and found that peritoneal carcinomatosis on CT was important predictor of suboptimal cytoreduction. ${ }^{4}$ Among the various CT parameters, Ferrandina et al had found bowel mesentry involvement and diaphragmatic disease as better predictors of surgical outcome and integration of ECOGPS with CT parameters had improved the predictive power of $\mathrm{CT}^{7}{ }^{7}$ But in present study none of the CT parameter was statistically significant in the prediction of surgical outcome on univariate analysis (Table 3). Although, Omental extension to spleen, lessersac, stomach and involvement of suprarenal aortic lymphnodes had $100 \%$ specificity and PPV in the prediction of suboptimal cytoreduction.

The optimal cytoreduction rate in present study was $56.1 \%$ overall, but it was only $37.5 \%$ for primary debulking group. In various other studies optimal cytoreduction rates range from $40-80 \% .^{12-17}$ It was observed that the cytoreduction rate exhibit variations, when done by gynaecologists in comparison with gynaecologic oncologist. The optimal cytoreduction rate is much higher when performed by gynaecologic oncologist almost ranging between $75-90 \% .{ }^{18-22}$ Surgeon factors are important in formulating a predictive model which adversely affect the surgical outcome. This study was performed in an institution where the surgeries were performed by gynaecologists not by gynecologic oncologists which has impact on the optimal cytoreduction rate.

The limitations of the study include the small sample size due to short duration of the study. Both primary debulking and interval debulking patients were included in the study which would have altered the study outcome. During the study period, we had more women undergoing interval debulking in comparison to primary cytoreduction, which was attributed to treating physician's discretion based on clinical and CT parameters. Even though, Omental extension and involvement of suprarenal aortic lymphnodes had $100 \%$ specificity and PPV, they were not statistically significant because very few patients had these findings.

MRI is another tool studied for prediction of surgical outcome in ovarian cancer. It has the accuracy of 93-96\% in the prediction of surgical outcome. MRI is as accurate as CT in the evaluation of ovarian tumor spread but, it is seldom included in routine clinical practice. ${ }^{23}$ Laparoscopy is an invasive tool used for prediction of resectability of advanced ovarian tumors. Fagotti et al developed a laparoscopic based prediction model which was found to be a reliable and flexible predictive tool in the evaluation of feasibility of optimal cytoreduction. ${ }^{24}$
Even though, CT served as a valid tool in the preoperative prediction of feasibility of optimal surgical outcome in advanced ovarian malignancy, these results cannot be extrapolated to the general population nor this can be universally applied clinically in determining the mode of treatment. The reproducibility of the findings of any predictive model relies upon, uniform surgical principles and similar optimal cytoreduction rates, which is impractical to achieve on universal basis. Hence, CT based predictive models should be used with vigilance in selecting treatment options for advanced ovarian tumor patients and caution needs to be exercised, while avoiding unnecessary exploration and also in withholding the necessary exploration based solely on its results, as it can significantly impact the survival outcome. Future studies are required to validate the findings of the present study on a larger scale. The need for other novel predictive model could be an area of potential research.

\section{Funding: No funding sources}

Conflict of interest: None declared

Ethical approval: The study was approved by the Institutional Ethics Committee

\section{REFERENCES}

1. Martinek IE, Kehoe S. When should surgical cytoreduction in advanced ovarian cancer take place? J oncol. 2010;2010:1-6.

2. Bristow RE. Primary cytoreductive surgery for advanced stage ovarian cancer:Indications for radical resection. Cancerologia 2. 2007; Suppl1:s31-s36.

3. Tangjitgamol S, Hanprasertpong J, Cubelli M, Zamagni C. Neoadjuvant chemotherapy and cytoreductive surgery in epithelial ovarian cancer. World J Obstet Gynecol. 2013;2(4):153-66.

4. Mousavi AS, Mazhari M, Mitra M, Gurlani MM, Behtash N, Akhavan S. Can primary optimal cytoreduction be predicted in advanced epithelial ovarian cancer preoperatively? World J Surg Oncol. 2010;8:11.

5. Dowdy SC, Mullany SA, Brandt KR, Huppert BJ, Cliby WA. The utility of CT scans in predicting the suboptimal cytoreductive surgery in women with advanced ovarian carcinoma. Cancer. 2004;101(2):346-52.

6. Hoskins WJ, McGurie WP, Brady MF, Homseley HD, Creasman WT, Berman M et al. The effect of diameter of largest residual disease on survival after primary cytoreductive surgery in patients with suboptimal residual epithelial ovarian carcinoma. Am J Obstet Gynecol. 1994;170:974-80.

7. Ferrandina G, Sallustio G, Fagotti A, Vizzielli G, Paglia A, Cucci E et al. Role of CT scan based and clinical evaluation in the preoperative prediction of optimal cytoreduction in advanced ovarian cancer: a prospective trial. BJC. 2009;101:1066-73.

8. Nelson BE, Rosenfield AT, Schwartz PE. Preoperative abdominopelvic computed tomographic 
prediction of optimal cytoreduction in epithelial ovarian carcinoma. J Clin Oncol. 1993;11(1):166-72.

9. Meyer JI, Kennedy AW, Friedman R, Ayoub A, Zepp RC. Ovarian carcinoma: value of CT in predicting success of debulking surgery. Am J Roentgenol. 1995; 165(4):875-8.

10. Bristow RE, Duska LR, Lambrou NC, Fishman EK, O'Neill MJ, Trimble E et al. A model for predicting surgical outcome in patients with advanced ovarian carcinoma using computed tomography. Cancer. 2000;89(7):1532-40.

11. Axtell AE, Lee MH, Bristow RE, Dowdy SC, Cliby WA, Raman S et al. Multi-institutional reciprocal validation study of computed tomography predictors of suboptimal primary cytoreduction in patients with advanced ovarian cancer. J Clin Oncol. 2007;25(4):384-9.

12. Borley J, Wilhelm-Benartzi C, Yazbek J, Williamson R, Bharwani N, Stewart V et al. Radiological predictors of cytoreductive outcomes in patients with advanced ovarian cancer. BJOG. 2015;122(6):843-9.

13. Neijt JP, ten Bokkel Huinink WW, van der Burg ME, van Oosterom AT, Willemse PH, Heintz AP et al. Randomized trial comparing two combination chemotherapy regimens (CHAP-5 v CP) in advanced ovarian carcinoma. J Clin Oncol. 1987;5(8):1157-68.

14. Hoskins WJ, Bundy BN, Thigpen JT, Omura GA. The influence of cytoreductive surgery on recurrence-free interval and survival in small-volume stage III epithelial ovarian cancer: a Gynecologic Oncology Group Study. Gynecol Oncol. 1992;47:159-66.

15. Bertelsen K. Tumor reduction surgery and long-term survival in advanced ovarian cancer: a DACOVA study. Gynecol Oncol. 1990;38:2039.

16. Venesmaa P. Epithelial ovarian cancer: impact of surgery and chemotherapy on survival during $1977-$ 1990. Obstet Gynecol. 1994;84:8-11.

17. Dauplat J, Le Bouëdec G, Pomel C, Scherer C. Cytoreductive surgery for advanced stages of ovarian cancer. Semin Surg Oncol. 2000;19(1):42-8.
18. Piver MS, Lele SB, Marchetti DL, Baker TR, Tsukada Y, Emrich LJ. Impact of aggressive debulking surgery and cisplatin-based chemotherapy on progression free survival in stage III and IV ovarian carcinoma. J Clin Oncol.1988;6:983-9.

19. Wu PC, Lang JH, Huang RL, Qu JY, Wang H, Tang MY et al. Lymph node metastasis and retroperitoneal lymphadenectomy in ovarian cancer. Baillieres Clin Obstet Gynaecol. 1989;3:143-55.

20. Eisenkop SM, Spirtos NM, Montag TW, Nalick RH, Wang HJ. The impact of subspecialty training on the management of advanced ovarian cancer. Gynecol Oncol.1992;47:203-9.

21. Michel G, De Iaco P, Castaigne D, el-Hassan MJ, Lobreglio R, Lhommé $\mathrm{C}$ et al. Extensive cytoreductive surgery in advanced ovarian carcinoma. Eur J Gynaec Oncol. 1997;18:9-15.

22. Eisenkop SM, Friedman RL, Wang HJ. Complete cytoreductive surgery is feasible and maximizes survival in patients with advanced epithelial ovarian cancer: a prospective study. Gynecol Oncol. 1998;69:103=8.

23. Iyer VR, Lee SI. MRI, CT and PET/CT for Ovarian Cancer Detection and Adnexal Lesion Characterization. Am J Roentgenol. 2010;194:31121.

24. Fagotti A, Ferrandina G, Fanfani F, Garganese G, Vizzielli G, Carone et al. Prospective validation of a laparoscopic predictive model for optimal cytoreduction in advanced ovarian carcinoma. Am J Obstet Gynecol. 2008;199:642.e1-642.e6.

Cite this article as: Nithya S, Jayalakshmi D, Barathi D, Dubashi B. Preoperative prediction of surgical outcome in advanced ovarian cancer by computed tomographic scan and Eastern Cooperative Oncology Group-performance status. Int J Reprod Contracept Obstet Gynecol 2018;7:3672-7. 